\title{
LA CAÍDA DE UNA ARTESANÍA: CESTERÍA EN SAN JUAN GUELAVIA, OAXACA*
}

\author{
THE COLLAPSE OF A CRAFT: BASKETMAKING \\ IN SAN JUAN GUELAVIA, OAXACA
}

\author{
Jeffrey H. Cohen ${ }^{1}$, Anjali Browning ${ }^{2}$ y Francisco Alejandro Montiel Ishino ${ }^{3}$
}

\begin{abstract}
Los artesanos oaxaqueños son célebres por la calidad de sus trabajos, el éxito de sus negocios y la capacidad de sus productos para trascender en el espacio y el tiempo. Los tejedores de algodón y textiles de lana, los fabricantes de cerámica de barro y más recientemente talladores de madera, que hacen alebrijes (animales de madera pintada), producen artículos que son comprados y vendidos en el mercado internacional y son exhibidos mundialmente en las colecciones de museos. Sin embargo, hay artesanías en Oaxaca que no son viables en el mercado y no aparecen en colecciones internacionales. En este documento examinamos la producción de canastas en la comunidad de San Juan Guelavia. Argumentamos que la caída en el mercado refleja tres cambios críticos: primero, una disminución en el uso local; segundo, un alza en los costos de producción; y tercero, una falta de apoyo de exportadores y una incapacidad para involucrarse en el mercado de exportación.
\end{abstract}

Palabras claves: mercaderías, mercados, cestería, México, economía, globalización.

Oaxacan artisans are celebrated for the quality of their work, their business success, and the ability of their goods to transcend space and time. Weavers of cotton and woolen textiles, potters, and most recently wood carvers who make alebrijes (painted wooden animals) produce goods that are bought and sold on the international market and appear in museum collections world-wide. Nevertheless, there are crafts in Oaxaca that are not viable in the current market and that do not show up in international collections. In this paper, we examine one such craft: basket making in the community of San Juan Guelavia. We argue that the decline in the market for these goods reflects several changes: first, a decline in local use; second, a rise in the costs of production; and third, a lack of support by exporters and an inability to engage the export or tourist markets. In response, local producers have moved into wage labor (locally and through migration) to secure their incomes.

Key words: Crafts, markets, basketry, Mexico, economics, globalization.

\section{El Problema}

Los estudios sobre los productores de artesanías en Oaxaca, México, se han enfocado en el éxito de venta y no en el modo en que los productores campesinos indígenas crean nuevos nichos para los artículos que ellos producen (Chibnik 2003; Clements 1990; Stephen 1987; Wood 1996; Wood 2000). Pero qué hay de las comunidades de productores que no tienen éxito, ¿qué pasa cuando los artesanos fallan en encontrar un mercado para sus productos? Este documento examina dicha situación. San Juan Guelavia, Oaxaca, es una comunidad zapoteca en la rama oriental de los valles centrales del Estado (Figura 1) y alberga a los fabricantes de canastas (llamadas así en lugar de cesta, como se usa en España) cuyo mercado local ha desaparecido, al ritmo del alza de los costos de producción.

Examinar la caída de la cestería y el colapso del mercado para canastas terminadas nos ayuda a entender mejor los retos que enfrentan los productores locales cuando intentan involucrarse en el mercado y en los patrones globales de consumo y gusto. El ejemplo de San Juan Guelavia también nos habla acerca del papel que juega el patrocinio (esto es, el apoyo de una mercadería por intermediarios y

* Ponencia presentada en la Mesa "Textiles tradicionales americanos. Significados de una actividad tradicional en el contexto de la globalización”, organizada por Cecilia Pérez de Micou, Liliana Ulloa y Elayne Zorn, en el $52^{\circ}$ Congreso Internacional de Americanistas, Sevilla, 17 al 21 de julio de 2006. La versión final en español fue revisada por Pablo Espinoza.

1 Departamento de Antropología, The Ohio State University, 244 Lord Hall, 124 W. $17^{\text {th }}$ Ave. Columbus, OH 43210. cohen.319@osu.edu

2 University of California, San Diego 9500 Gilman Drive, Mail Code 0510, La Jolla, CA 92093-0510 anjalibrowning@ ca.rr.com

3 University of Southern Florida, Departamento de Antropología, 4202 East Fowler Ave, SOC107, Tampa, FL 33620-7200. f.montieli@gmail.com 
compradores poderosos) para los productores de mercaderías. La mayoría de los turistas que viajan hacia Oaxaca conocen las ricas tradiciones de los oficios en los valles centrales y visitan a los tejedores en Teotitlán del Valle (Stephen 1993; Wood 2000) y a los talladores de madera en Arrazolo y San Martín Tilcajete (Chibnik 2003), entre otros lugares (ver p.ej., Cook 1993). Sin embargo, aquellos mismos turistas con frecuencia fallan en patrocinar a los tejedores en Santa Ana del Valle, Villa Díaz Ordaz y San Miguel del Valle y a los fabricantes de canastas, quienes llaman hogar a San Juan Guelavia (ver Cohen 1998) ${ }^{1}$.

\section{San Juan Guelavia}

San Juan Guelavia es una comunidad zapoteca de 2.919 personas (INEGI 2000), donde el 90\% es bilingüe (DIGEPO 1999). En otras palabras, la mayoría de los ciudadanos de Guelavia hablan un dialecto local del zapoteca, así como español. Además, siguen prácticas y tradiciones que son únicas (o al menos los pobladores suponen que son únicas y excepcionales) e incluye un sistema de carga compleja (religiosa y jerarquía política de control civil dentro del pueblo) y la práctica de tequio (trabajo comunal) para el manejo de la comunidad (Acevedo y Restrepo 1991; Beals 1970; Cohen 1999).

El pueblo data de cientos de años. Fundado originalmente por jornaleros del maíz y amarrados al centro regional de Macuilxóchitl (García 1990), fue conocido por su producción de sal. Aparece inicialmente en documentos españoles en agosto de 1580 con el nombre de San Juan Quelaa (Francisco del Paso y Troncoso, citado en Mendieta y Núñez 1960:215)2. Mientras que la fabricación de canastas es celebrada en la comunidad y descrita frecuentemente como un arte tradicional con raíces profundas, es una industria relativamente nueva, introducida en 1946 por un grupo de estadounidenses que planearon originalmente exportar los productos terminados a los Estados Unidos (Mendieta y Núñez 1960:283).

La vida en San Juan Guelavia está marcada por varios indicadores de pobreza. Cerca de la cuarta parte de la población es analfabeta y sólo el $48 \%$ de los adultos de la comunidad terminaron su escuela elemental (primaria), además, cerca del $80 \%$ de los hogares de la comunidad no gana un salario para vivir (alrededor de 10 U\$S al día, DIGEPO 1999). Adicionalmente, el $75 \%$ de los hogares no tiene acceso a drenajes y el $98 \%$ no tiene agua potable. Hay poca infraestructura en la comunidad y más allá de unas cuantas tiendas locales, la mayoría de los pobladores viaja en taxis a las ciudades cercanas -incluyendo Tlacolula (aproximadamente a $10 \mathrm{~km}$ hacia el oriente) y la ciudad de Oaxaca (37 km hacia el poniente)- para hacer sus compras.

Debido a que en la actualidad la comunidad carece de una industria local y de infraestructura para apoyar la inversión económica, la mayoría de los pobladores de Guelavia se gana la vida con el cultivo de pequeñas parcelas (milpas), el pastoreo de animales, la venta de vegetales cosechados y de las canastas que producen. Además, obtienen sueldos como mano de obra en Oaxaca o como inmigrantes dentro del país o hacia Estados Unidos. La mayoría de los hombres que no emigra a los Estados Unidos o a un destino interno encuentran trabajo en las vecindades de Oaxaca. Las mujeres de Guelavia se involucran en un sinnúmero de actividades, que realzan la situación económica de sus hogares, incluyendo la preparación local de tortillas y su venta tanto en Guelavia como en las cercanías de Tlacolula. Muchas veces, las mujeres ganan en sus hogares tanto, si no es más, que los hombres a través de estos esfuerzos, aportando fondos críticos para la supervivencia y mantenimiento del hogar (Stephen 2005).

Muchos pobladores de Guelavia mantienen sus hogares a través de la migración interna e internacional. Una encuesta reciente de Guelavia encontró que el $60 \%$ de los hogares de la comunidad incluía miembros que han emigrado hacia los Estados Unidos (Cohen 2004), predominantemente al área de Los Ángeles (California), donde viven con parientes y amigos, enviando el dinero a sus casas cada dos meses para sostener a sus familias. Los emigrantes encuentran trabajo, en general, en la industria de servicio como ayudantes de cocina y lavaplatos.

Históricamente, Guelavia fue conocida por sus tierras fértiles y la producción y venta de sal. Antes de las reformas agrarias los jornaleros producían maíz, trigo y alfalfa en tierras de riego hacia el norte del pueblo y en los límites de Santa Ana del Valle, Tlacolula y Santa María Guelace (Mendieta y Núñez 1960:220). Hoy en día, la mayoría del riego ha desaparecido y las tierras agrícolas de la comunidad sufren una alta salinización, algo que Mendieta y Núñez (1960) observan a principios de 1950. Los pobladores se quejaban de la degradación 
del suelo y la salinización de pozos; un hombre de edad avanzada describió la situación como que su tierra estaba "triste" y no produciría bien. Sin embargo, cerca del $80 \%$ de las familias de la comunidad continúan trabajándolas, sembrando maíz y alfalfa en un promedio de 2,25 hectáreas. En el bienio 2000-2002 una familia producía maíz para ocho de los doce meses que necesitaba.

La elaboración de canastas fue introducida en 1946 por hombres de negocios de los Estados Unidos y pronto se hizo popular. En 1960, casi el $60 \%$ de las familias de Guelavia participaban de la misma actividad. Mendieta y Núñez señalaron que en la década de 1950 los fabricantes de canastas de Guelavia dependían de esa producción en más del $50 \%$ de sus ingresos. Los reportes de Mendieta y Núñez indican que para una inversión de aproximadamente 4 pesos (moneda de México), gastados en materiales, una familia puede ganar cerca de 16,5 pesos vendiendo artículos terminados. Sin embargo, las exportaciones nunca despegaron. Los hombres de negocios de los Estados Unidos que establecieron la fabricación de canastas no regresaron y las ventas fueron hechas localmente a otros oaxaqueños y en mercados de la zona (Mendieta y Núñez 1960:283-284).

Mientras que la tierra de Guelavia favorece la producción agrícola, el carrizo (nombre con el que se conoce la caña usada en la fabricación de canastas) no crece localmente en abundancia, por lo que la mayoría de los fabricantes de canastas deben viajar a otras poblaciones de la zona (incluyendo Tlacolula) para comprarlo. Muchas familias habían participado en la elaboración después de la llegada de los empresarios y produjeron petates (tapetes de caña que se usan para dormir) así como canastas grandes y chicas. Las grandes (que miden hasta un metro de altura y 50 a $80 \mathrm{~cm}$ de ancho) se usaban para guardar el maíz cosechado, mientras que las mujeres usaban las más pequeñas para guardar provisiones de abarrotes comprados en los mercados locales.

La industria contemporánea del canasto está colapsando rápidamente. Pocas familias las hacen y hay pocas vías para la venta de piezas terminadas. Los costos de elaboración también se han incrementado en la última década, forzando a muchas familias a dejar la producción. Ninguna actividad local en Guelavia ha tomado el lugar de la canastería $\mathrm{y}$, actualmente, menos del $25 \%$ de las familias de la comunidad continúan en esa actividad ${ }^{3}$. Para aquellas que lo hacen, la elaboración de canastas es descrita como una actividad que llena el tiempo. Esto marca un cambio importante en la forma que los pobladores de Guelavia encuadran este oficio, ya que en su inicio fue visto como una nueva e importante fuente de trabajo local, una forma para construir la economía de la población y una actividad lucrativa potencial con excelentes utilidades en inversiones (Mendieta y Núñez 1960:280-283). A fines de la década de 1990 y en los primeros años de este siglo la fabricación de canastas aún resultaba favorable. El cambio en la producción es indicativo de un cambio en la demanda y de las alzas en costos de producción, así como el incremento general en el costo de la vida. Cuando los costos de producción subieron y las utilidades declinaron, las familias descubrieron que podían ganar salarios más altos a través de la migración y, de hecho, las tasas de migración se incrementaron a mediados de la década de 1990, cuando las familias se enfrentaron con las reformas neoliberales (Otero 1999) ${ }^{4}$.

Bourdieu (1990:89) argumenta que si la producción tiene éxito económicamente, los trabajadores deben producir algo de valor (ver discusión en Cook 2004). En otras palabras, en el caso de Guelavia, los fabricantes de canastas deben producir artículos que puedan vender al consumidor que valora lo que ellos hacen. Bourdieu asevera que el trabajo "también debe producir una creencia en el valor de la misma actividad de producción" (Bourdieu 1990:89). Así, la actividad no sólo debe producir artículos valiosos, sino que ella misma debe ser evaluada como una actividad que le importa al fabricante. Esto no ocurre entre los pobladores de Guelavia ya que, como se estableció, ellos la consideran como algo para llenar un día vacío. Mientras que los tejedores en Santa Ana del Valle algunas veces describen su trabajo en términos similares (es un negocio difícil de poca paga), la mayoría de ellos viven de su trabajo.

Los talladores de madera también celebran su trabajo. En una entrevista relacionada con migración en 2001, uno de San Martín Tilcajete comentó, ¿por qué emigraría si estoy muy bien aquí? Puedo gastar miles de pesos cruzando la frontera, o me puedo quedar aquí y hacer miles de pesos vendiendo mis alebrijes". Los dividendos potenciales de la emigración no compiten con el eventual obtenido, asociado con la producción de alebrijes (Chibnik 2001, 2003). Compárese esto con la actitud de don Benito, un fabricante de San Juan Guelavia, quien comentó, 
"tú sabes, esto nos mantiene [mi familia] juntos, pero no podemos ganar dinero".

\section{Fabricación de Canastas}

Como hemos visto, la vida en San Juan Guelavia gira alrededor de la agricultura aun cuando la tasa de emigración a destinos internos e internacionales se ha incrementado. Para los hombres en el poblado, la agricultura ocupa el día durante la temporada alta; la mayoría de las familias argumentan que ésta es más que una forma de ganarse la vida. Ser dueño de la tierra es un signo de "estatus" y pertenencia a la comunidad, ya que la tierra crea una conexión importante con el poblado y las tradiciones locales (González 2001). La elaboración de canastas ocupó ese lugar para las familias del área en el pasado. Después de su establecimiento, en la década de 1940, fue algo que hacían para ganar dinero, pero también muy pronto se convirtió en una tradición local. De hecho, varios individuos describieron a la cestería como "nuestra mercadería y algo que todos hacen"5.

Unas cuantas familias que continúan en la producción de canastas la consideran como parte de un conjunto de prácticas estratégicas más amplio para ganarse la vida. Un miembro de una familia es enviado a los Estados Unidos para trabajar en la construcción o en servicios, mientras que otro viajará a Oaxaca para el trabajo diario. Los miembros que se quedan en Guelavia hacen canastas, siembran y participan en el sistema de carga o tienen cargos políticos. Un modelo de esto es la familia Martínez: don Benito Martínez, la cabeza masculina del hogar, combinó la elaboración de canastas y la agricultura como una forma de ganar dinero, pero también para abastecer de maíz a la familia. Dos de sus hijos ayudaron con la agricultura y la canastería, mientras que una hija dividió su tiempo entre esta actividad y la escuela (ella había estado en un programa de entrenamiento de cultivo en Oaxaca). La señora Martínez vendía tortillas, se encargó de la casa (preparando alimentos, limpieza, etc.) y algunas veces participó en la elaboración de canastas. Finalmente, el hijo mayor había emigrado en 1999 y trabajaba en un restaurante en Santa Mónica, California. Él enviaba dinero en forma regular que se usaba para cubrir los costos de comida y mantenimiento de la casa.

Durante el verano de 2000 don Benito explicó en detalle la manufactura cestera; indicó la forma en "que era antes", cuando la caña estaba disponible y era barata, cómo aprendió de su padre, de niño, el tejido de canastas así como éste lo hizo de su abuelo. Esto es, tal vez, como si la fabricación de canastas fuera una leyenda de reciente arribo al área. Sin embargo, en 2001, siendo parte de la comunidad por casi 60 años, don Benito nos dijo que "trabajaríamos juntos. Primero reunir la caña, cortarla y tejer las canastas. Fue un trabajo bueno y quisimos hacerlo, también nos fue bien" (julio de 2000, San Juan Guelavia).

Don Benito ha elaborado canastas por más de 35 años, y a pesar que se quejaba de esta forma de ganar dinero, no dio indicios de que querer abandonarla. Tejió canastas para la cosecha, para los vendedores de flores y canastas especiales para decoración, para poner productos así como para regalos durante los días festivos.

La manufactura de canastas empieza con la recolección y el corte del carrizo, que crece en Guelavia, pero nunca en abundancia. En el pasado las familias podían cosecharlo sin costo a lo largo del municipio, si estaba disponible. El único requisito era que el artesano tuviera un registro de servicio activo en el sistema de puestos de gobierno de la comunidad. Sin embargo, la falta de carrizo local forzó a la mayoría de los fabricantes a viajar a los poblados vecinos, con frecuencia rentando una camioneta pequeña para transportar a casa la cosecha de caña de una semana.

Entre 1940 y 1950, una carga de carrizo costaba alrededor de 4 pesos, para un abasto que duraría cerca de un mes, hoy la caña cuesta 200 pesos aproximadamente. Habitualmente la compran cada dos meses, para ello contratan una camioneta con un cargo adicional de 200 pesos, este costo se divide entre varios tejedores. Una vez que una carga de carrizo es entregada en casa, hay una pequeña cooperación adicional por parte de cada artesano.

El precio de la caña ha subido en la última década (un patrón similar ha ocurrido con el tejido, ver Stephen 2005). Don Benito enfatizó que a mediados de 1990 la carga de un mes costaba entre 80 y 100 pesos, cerca de la mitad del precio actual, y una de éstas puede ser triplicada cuando se convierte en canastas terminadas. Además, el costo de la vida se ha acelerado, así como continúa en aumento la pobreza en la región (Wodon et al. 2003).

Una vez que la caña es comprada o cosechada se prepara en un proceso de pasos múltiples. Primero, se corta a la medida y se limpia; luego se rasura con un cuchillo, se retira la pulpa interna suave del 
carrizo y se deja una superficie, en la que se puede hacer capas para trabajar con ellas. Después la caña se ahúma por corto tiempo y se calienta al fuego para hacerla maleable. Si es necesario, también se le aplica color con anilinas, a menudo rojo y verde, los colores nacionales de México. Los costos aquí son mínimos y pueden incluir la leña, que algunas veces es comprada.

En el paso tres empieza el proceso de confección del canasto. Los pobladores de Guelavia hacen varios tipos, pero generalmente dos estilos dominan: canastas pequeñas con "agarraderas", usadas por las mujeres en la compra de productos del mercado (frutas y vegetales), y las grandes que los hombres se amarran en sus espaldas y llenan con maíz cosechado. Después de formar un cuadro de muy poca anchura y tiras de caña más gruesas, el cestero empieza a tejer la base del canasto, trabajando del centro hacia fuera, a veces con una caña más delgada que la de los lados. El tejedor encuentra un lugar sombreado, bonito para hacer su trabajo, tejiendo pronto la caña para crear la base y los lados. En la parte superior del canasto, una hilera de caña extra es tejida para crear un "labio" que cubra y dé acabado a la parte superior del cuadro o marco. Para canastas pequeñas, una "agarradera" (siempre teñida) se envuelve para facilitar su manejo. El proceso no consume mucho tiempo y un buen tejedor puede producir una docena o más en alrededor de una semana. Don Benito nos dijo que un fabricante necesita dos días para preparar su caña y alrededor de tres días para tejerla. Dependiendo del tamaño, puede terminar 10 o más en una semana.

\section{El Mercado y su Caída}

Algunas veces los cesteros venden sus productos a intermediarios y compradores, pero la mayoría lo hacen directamente a los consumidores; las familias, envían a un miembro al mercado a ofrecer las mercaderías. Los compradores, quienes adquieren las canastas terminadas por contrato o por pieza, las revenden a consumidores, comerciantes y dueños de tiendas. Los precios oscilan entre 50 pesos para las canastas típicas, pequeñas, y 200 para las de trabajo detallado. Sin embargo, los artesanos enfatizaron que los precios de canastas terminadas no eran fijos y pueden fluctuar a lo largo del año. Aún más, aunque los costos de las materias primas se hayan incrementado, el precio de los productos terminados ha permanecido sin cambios.
Mendieta y Núñez (1960) anotaron que en la década de 1950 la familia típica de Guelavia ganaba más de la mitad de sus ingresos a través de la venta de canastas terminadas, cerca de 5,5 pesos al día en promedio, y necesitaban sólo un poco más de 1 peso para cubrir gastos. En marzo de 2006 un fabricante de canastas ganó 600 pesos por cada 200 invertidos; sin embargo, descubrimos que las familias estaban gastando con frecuencia alrededor de 200 pesos diarios promedio en comida (alrededor de 1.400 por semana) ${ }^{6}$. Para cubrir gastos, más de la mitad de la comunidad contó con remesas de un miembro que había emigrado a los Estados Unidos.

Los cesteros no pueden ganar lo suficiente con su arte, ni siquiera cubren una fracción de los gastos diarios y, como nos dijo don Epifano, "tú no vives de la fabricación de canastas, tienes que hacer algo más". Para él esto significó tener que apoyarse en una hija que vive en los Estados Unidos y dos hijos que se quedaron en el poblado, uno trabaja en la construcción, en Oaxaca, y el otro se dedica al pastoreo de ovejas.

Las ventas locales se mantienen críticas para los fabricantes de canastas que sigue el itinerario de los mercados semanales a lo largo de Oaxaca. Además de varios de éstos en la capital del Estado (Centro de Abastos, Mercado 20 de noviembre), cada día los vendedores del área viajan a los centros regionales para ofrecer sus productos (Cook y Diskin 1976). El mercado más importante para San Juan Guelavia es el mercado del domingo en Tlacolula que está a sólo unos kilómetros, y es frecuentado por grandes multitudes de gente local y turistas que buscan artesanías del área. Sin embargo, las ventas son lentas, no hay garantía de ingresos ni coordinación entre los canasteros. No se organizan para vender y/o coordinar los precios. En lugar de eso, estos artesanos son conocidos por perjudicarse entre ellos cuando se trata de precios, regularmente debilitan a la competencia para hacer una venta aun al costo de bajar el ingreso potencial. La demanda es baja, con frecuencia es difícil encontrar un comprador para los artículos terminados y los valores por las canastas se mantienen parejos. Adicionalmente, el costo de materias primas que se incrementa reduce las utilidades.

Asimismo, varios factores influyen en la actividad cestera y conducen las ventas a la baja de los artículos terminados. Primero, la llegada de piezas de plástico baratas y el uso de bolsas de este material en los mercados han provocado que 
se tornen obsoletas las canastas de carrizo. Éstas se gastan más que las bolsas plásticas, de modo que el uso de estas últimas hace que los compradores ahorren dinero.

El valor y la atracción de las bolsas de plástico (en inglés ready made plastic bags) contrastan con el "estatus" que se asocia con las canastas de caña bien hechas. Uno puede encontrar mujeres oaxaqueñas sopesando cuidadosamente las canastas de Guelavia en el mercado semanal de Tlacolula, pero es un símbolo del campo, no de un comprador urbano y de un negocio moderno. Lo hecho a mano es una tradición local y un signo de Guelavia, pero un signo de un estilo de vida rural.

Muchas mujeres locales continúan usando las canastas y la mayoría de los hogares rurales tienen estos cestos grandes y chicos. Además, a diferencia de las bolsas desechables, un canasto de Guelavia es fuerte y puede durar años. Por eso su compra es poco frecuente, sólo cuando la caña se seca o se rompe.

Una segunda preocupación que ha limitado la venta es que las canastas son atacadas por insectos. La mayoría de las familias nos dijo que aman las canastas, pero que las alternativas de plástico eran fáciles de mantener limpias sin infestación de roedores e insectos. Las plagas se comen la caña, se esconden en las rendijas y anidan dentro y debajo de las canastas. Más crítico aún, las plagas consumen el maíz contaminando las pilas de granos almacenadas. Finalmente, los cestos plásticos son más ligeros y es más fácil deshacerse de ellos.

Tercero, y de importancia crítica, la fabricación de canastas, a diferencia del tejido de lana y algodón, alebrijes y joyería, no tiene lugar en el mercado de exportación, no hay patrocinadores del arte ni quién lo promueva. Los patrocinadores de arte ayudan al artesano a cubrir los costos de producción, comprar productos y abrir nuevos espacios para la venta (Little 2004). El artesano, con el apoyo del patrocinador, no tiene que sacar mucho dinero para la producción y acceder a mercados nuevos y distantes, lo cual crea más oportunidades de ingresos. Finalmente, los patrocinadores ayudan a los artesanos a seguir las demandas cambiantes y los cambios de la moda. La ayuda de un patrocinador es significativa para el éxito de los tejedores de textiles de lana en Teotitlán del Valle (Wood 2000) y los fabricantes de alebrijes en San Martín Tilcajete y Arrazola (Chibnik 2003). Pero ésta no existe entre los cesteros de Guelavia aún cuando Mendieta y Núñez (1960) argumentan que fue decisivo en la fundación del oficio. La falta de interés en las canastas tiene un gran impacto, cuando se piensa en el papel crítico que juegan en el arte y las tradiciones del nativo de Norteamérica. No sólo son valoradas por los museos en Norteamérica como señal de identidad, sino también por su gran valor como piezas de colección y con frecuencia cuestan miles de dólares (ver discusión en Hill 2001).

Por qué las canastas de Guelavia carecen de valor en el mercado turístico local o de exportación o como piezas de museo es una interrogante. Una posibilidad es porque es un oficio relativamente nuevo para la comunidad, no es tradicional. Pero entonces debemos preguntarnos, por qué otras artes introducidas son aceptadas por los consumidores y celebradas en el mercado.

Los tejedores en Teotitlán del Valle y Santa Ana del Valle reconocen las raíces de sus textiles de lana tradicionales en el distante pasado indígena colonial o precolonial (ver p.ej., Cohen 1999; Stephen 1991; Wood 2000). Los tejedores y vendedores describen los tapetes (alfombras y tapices tejidos a mano) como sensibilidades e imágenes indígenas que reflejan e incluyen patrones que son conjurados en los sueños del tejedor, reflejan sitios arqueológicos locales, así como los gustos cambiantes de consumidores internacionales (Stephen 1993), nunca parecen reflejar las exigencias del mercado dentro del cual la producción está encuadrada. Los tejedores producen artículos terminados específicamente para cumplir con los estilos, colores y presupuestos de turistas y del mercado de exportación. Además, la producción, aunque basada en lo doméstico y descrita como una actividad familiar, no sigue un modelo precapitalista, se organiza alrededor de talleres, con formas de trabajo por contrato, como mano de obra, ya que ellos satisfacen la demanda de comerciantes quienes revenden a turistas o exportadores (Cook 2004; Stephen 2005; Wood 2000).

$\mathrm{Al}$ igual que el tejido de canastas, el tallado de madera es una tradición inventada que data de la segunda parte del siglo XX, es el resultado de la combinación de la perspicacia de los comerciantes en la ciudad de Oaxaca con las habilidades de artesanos en Arrazola y, después, en San Martín Tilcajete (Chibnik 2003), el tallado de madera es una actividad puramente económica. Chibnik (2003) anota que la mayoría de los talladores abandonarían los alebrijes si el mercado decae. Vendidos por miles y cotizados desde unos cuantos dólares 
hasta varios cientos (y fácilmente encontrados en el Internet, así como en tiendas de artesanías a lo largo de México y los Estados Unidos), los talladores se benefician de "la mala comunicación intercultural" (Chibnik 2003:243), o porque los consumidores asumen que los alebrijes están ligados a algún pasado primordial que refleja al México real.

El argumento de Chibnik, que los oficios exitosos malcomunican el significado, es similar a la opinión dada por Orlove y Rutz (1989:39), quienes argumentan que las mercancías "hacen surgir preguntas y presentan ambigüedades" para los consumidores. Entonces, para ellos, los textiles y alebrijes capturan ambigüedades que están vinculadas a imágenes fantasiosas de México, de ensueños e indígenas. Las canastas, por otro lado, son claramente de servicio (utilitario), no son soñadas, tampoco útiles para capturar un pasado imaginario; tal vez son productos puestos para ser usados por campesinos jornaleros. Jornaleros, gente que al turista no le gustaría conocer, que necesitan canastas para cargar y llevar cosechas y víveres.

Appadurai opina en forma similar cuando explora por qué ciertos productos capturan la imaginación (y la billetera) de los consumidores. Él sostiene que los productos exitosos (o tal vez los de valor) no se disfrutan por su materialidad (su uso local o indígena y significado), sino por algún otro significado u objetivo que es definido por el consumidor (Appadurai 2006:19). Los tapetes blancos y alebrijes capturan la imaginación; mientras que para bien o para mal, las canastas son una necesidad material y no hay nada de ensueño en ellas. En lugar de eso, su uso real es emblemático de lo rural, del trabajo duro y, tal vez, inclusive de la pobreza.

Los turistas ven las canastas en uso y llenas de productos o granos (como parte de una exhibición en un restaurante). Uno podría verlas amarradas a la espalda de un jornalero o llevadas por una mujer en el mercado, mientras que los alebrijes y textiles son exhibidos con arte en galerías y en Internet. Son coloridos, con frecuencia resaltan entre joyería y bellas artes, por eso no son presentados como útiles. Los locales no compran y no pueden adquirir alebrijes, no les alcanza, los costos son muy elevados, pero sí compran canastas.

La falla de las canastas en entrar al mercado local también refleja la naturaleza marginal de la economía detrás de su fabricación. Los cesteros ganan muy poco por su trabajo, es caro en comparación con las bolsas de plástico, tiene poco valor como producto. De ahí, a diferencia de los alebrijes y textiles que pueden atraer varios cientos de dólares a los dueños de las galerías, exportadores y comerciantes, los márgenes pequeños de utilidad en las canastas limitan el interés de los comerciantes. Además, los productores que venden directamente a los consumidores ganan muy poco para penetrar el mercado de exportación.

La falta de integración con galerías, turismo y los mercados de exportación es crítica para los productores locales. Primero, las canastas no se venden en tiendas para turistas. Durante nuestra estancia en Guelavia la gente preguntó en forma regular si nosotros "podríamos ayudar a convencer al Estado para organizar una cooperativa de fabricación de canastas". Varios líderes del poblado señalaron los programas de museo en Santa Ana del Valle y preguntaron, ¿por qué no podemos tener un museo también?" Nos siguieron diciendo que los promotores del programa de museo nunca visitaron Guelavia y que los líderes no pudieron obtener una cita con ellos en la ciudad. De hecho, Scrase (2003) argumenta que la falta de apoyo estatal y de esfuerzos no gubernamentales para apoyar la producción de la artesanía era sintomático de su producción en el Tercer Mundo condenando a la mayoría de artesanos a su fracaso económico.

Los fabricantes de canastas de Guelavia no tienen apoyo en posiciones oficiales; no hay promotores ni patrocinadores locales o foráneos de su arte. A diferencia del tejido en Teotitlán, que es celebrado en forma regular en la prensa y exhibido en galerías a lo largo de Estados Unidos y México (y vendido como bellas artes), las canastas de Guelavia son vistas como de mucha utilidad y carecen de valor. Las alianzas y apoyos que se han desarrollado alrededor del tejido y alebrijes incluyen mejoras en la comunicación, caminos, señaléticas, traducciones a otros idiomas y conexiones directas entre los productores textiles y guías de turistas. Los guías negocian con frecuencia con tejedores y talladores de madera a cambio de llevar turistas a sus talleres, también ganan un porcentaje pequeño por ingresos de las ventas. Los pobladores de Guelavia no tienen dichos apoyos, no hay mejoras por el desarrollo del turismo, la comunidad no trabaja con guías, no hay descripción de su oficio en libros de paseos (tours). El poblado tampoco es promovido como una posible alternativa en el itinerario seguido para visitar a los tejedores en Teotitlán del Valle, sitios arqueológicos en Mitla y alrededor de Tlacolula o el mercado de 
domingo en Tlacolula. De cierta forma, los cesteros en Guelavia son la antítesis de los tejedores en Teotitlán. Allí, y con el apoyo de los exportadores y patrocinadores, los tejedores encuentran por sí mismos una parte de las "cadenas complejas de subcontratar relaciones" (Wood 2000:185). Además, en Guelavia, no hay cadenas, hay pocos contratos y escasas oportunidades para enviar los productos terminados al mercado.

Esta situación no es el resultado de la mala suerte en la comunidad. Siendo que la fabricación de canastas empezó en forma prometedora y creció para incluir casi un $60 \%$ de hogares locales en la producción, el incremento no continuó a través de la década de 1990 y en los últimos años, decayó. El desarrollo de la comecialización de los alebrijes siguió un patrón similar; sin embargo, donde los fabricantes de canastas lucharon para sostener sus mercados, los talladores de madera llenaron un nicho con un producto que los consumidores continúan valorando y deseando. Tal vez algo más importante, los talladores de madera continúan trabajando en estrecha relación con comerciantes y dueños de galerías para crear, expandir y resaltar su mercado (Chibnik 2003). Los turistas requieren alebrijes, y como patrocinadores importantes han elevado los precios a través de su colección (ver Chibnik 2003). El tejido de textiles de lana sigue una trayectoria similar a los alebrijes. Teotitecos y tejedores de Santa Ana pusieron su esfuerzo en articularse con los vendedores para seguir los dictados de gusto y estilo y responder directamente a los deseos de los foráneos para productos diferentes. Así, a diferencia de los fabricantes de canastas, los tejedores responden al mercado y a la demanda, no al ciclo agrícola, ni a las necesidades de compradores locales.

\section{Conclusiones}

Hoy, la fabricación de canastas en Guelavia es verdaderamente un oficio sin futuro. Porque no hay interés por parte de los exportadores, por una falta de demanda local y por un creciente costo real de la producción; por esto, esta artesanía está decayendo. No es que los pobladores de Guelavia no entiendan su mercado o que no haya demanda para sus utensilios. A los cesteros de Guelavia les gustaría cambiar su mercado e inclusive ellos cambiar su producto, conectando las canastas con un nicho vinculado con el turista y el mercado de exportación en lugar de cubrir la demanda local.
Desafortunadamente, este es un cambio que parece imposible o que llegaría demasiado tarde. Además, y añadiendo a la dificultad de transitar a nuevas realidades de mercado, no hay patrocinadores presentes (ya sea de los Estados Unidos o México y /o de programas locales culturales) para reorganizar el oficio. El Estado mexicano no se ha interesado en esto a pesar de unas cuantas innovaciones que se han hecho en las últimas décadas y que pudieran atraer nuevos compradores o llenar nuevos nichos con este arte. Finalmente, son pocos los turistas que ven a las canastas como algo que vale la pena comprar. En otras palabras, es difícil o imposible para los fabricantes de canastas de Guelavia hacer una transición hacia una nueva clase de paradigma de producción.

El futuro de los cesteros de Guelavia es incierto. Tal vez la respuesta es dejar que el oficio muera. No podemos olvidar que esta artesanía, si Mendieta y Núñez (1960) están en lo correcto, es nada más que una tradición inventada; fundada bajo la creencia de que se abría una economía de exportación a los Estados Unidos. Aunque muchos artesanos ven poco valor en lo que hacen, los pobladores de Guelavia continúan luchando para balancear el trabajo y la emigración y muchos creen que si la elaboración de canastas funcionara, pudiera ser una actividad alterna que mantendría en el hogar a los jóvenes y limitaría la atracción de la emigración (ver Chibnik 2003; Cook 2004). Esta opinión fue expresada por Don Epifano, un hombre que ha pasado años como cestero, pero que también ha servido como presidente municipal del poblado en la década de 1990. Él quiso ver florecer su pueblo, pero fue realista y vio pocas oportunidades en el horizonte. Así los pobladores de Guelavia debieron dedicarse a otras actividades para ganarse la vida y balancear la necesidad de pagar por la comida, la educación, el entretenimiento al tiempo que intentaron preservar lo que muchos hoy ven como un arte tradicional. Desafortunadamente, hay poco espacio en este esquema para los fabricantes de canastas y sus productos.

Agradecimientos: Este documento fue desarrollado de un estudio de migración apoyado por la Fundación Nacional de Ciencias (National Science Foundation, BCS\# 9875539). El apoyo continuo fue proporcionado por el programa García-Robles Fulbright. Le agradecemos a la comunidad de San Juan Guelavia y a los cesteros que se tomaron el 
tiempo para sentarse a platicar con nosotros. Gracias también al Instituto Tecnológico Oaxaca, el Depto. de Antropología de la Universidad Estatal de Ohio,
Rafael Reyes Morales, Salvador López Plata, W. Warner Wood y Michael Chibnik. Gracias a los evaluadores por los comentarios.

\section{Referencias Citadas}

Acevedo, M.L. e I. Restrepo

1991 Los Valles Centrales de Oaxaca. Centro de Ecodesarrollo, Gobierno de Oaxaca, Oaxaca.

Appadurai, A.

2006 The thing itself. Public Culture 18:15-21.

Beals, R.

1970 Gifting, reciprocity, savings and credit in peasant Oaxaca. Southwestern Journal of Anthropology 26:231241.

Chibnik, M.

2001 Oaxacan wood carvers: Global markets and local work organizations. En Plural Globalities in Multiple Localities: New World Borders, editado por M.W. Rees y J. Smart, pp. 129-148. University Press of America, Lanham.

2003 Crafting Tradition: The Making and Marketing of Oaxacan Wood Carvings. University of Texas Press, Austin.

Clements, H.P.

1990 La historia de una comunidad artesana: Santo Tomás Jalieza: 1857-1940. En Lecturas Históricas del Estado de Oaxaca, Vol. IV, 1877-1930. INAH, Colección Regiones de México, Oaxaca.

Cohen, J.H.

1998 Craft production and the challenge of the global market: An artisans' cooperative in Oaxaca, Mexico. Human Organization 57:74-82.

1999 Cooperation and Community: Economy and Society in Oaxaca. University of Texas Press, Austin.

2004 The Culture of Migration in Southern Mexico. University of Texas Press, Austin.

Cook, S.

1993 Craft commodity production, market diversity, and differential rewards in Mexican capitalism today. En Crafts in the World Market: The Impact of Global Exchange on Middle American Artisans, editado por J. Nash, pp. 59-83. State University of New York Press, Albany.

2004 Understanding Commodity Cultures: Explorations in Economic Anthropology with Case Studies from Mexico. Rowman \& Littlefield Publishers, inc., Lanham.

Cook, S. y M. Diskin

1976 Markets in Oaxaca. University of Texas Press, Austin.

DIGEPO

1999 Oaxaca, Indicadores Socioeconómicos Índice y Grado en Marginación por Localidad (1995). Dirección General de Población de Oaxaca y Consejo Nacional de Población, Oaxaca.

García, A.E.

1990 San Juan Guelavia en la memoria Zapoteca. El Medio Milenio $\mathrm{N}^{\circ} 6$.

González, R.J.

2001 Zapotec Science: Farming and Food in the Northern Sierra of Oaxaca. University of Texas Press, Austin
Hill, S.H.

2001 Marketing traditions: Cherokee basketry and tourist economies. En Selling the Indian: Commercializing and Appropriating American Indian Culture, editado por C.J. Meyer y D. Royer, pp. 212-235. University of Arizona Press, Tucson.

INEGI

2000 Estadísticas Históricas de México. Tomos I y II. Aguascalientes; Instituto Nacional de Estadísticas, Geografía e Informática, México.

Little, W.E.

2004 Mayas in the Marketplace. University of Texas Press, Austin.

Mendieta y Núñez, L.

1960 Efectos Sociales de la Reforma Agraria en Tres Comunidades Ejidales de la República Mexicana. Universidad Nacional Autónoma de México, México.

Orlove, B.S. y H.J. Rutz

1989 Thinking about consumption: A social economy approach. En The Social Economy of Consumption, editado por H.J. Rutz y B.S. Orlove, pp. 1-57. Society for Economic Anthropology, Volume VI. University Press of America, Lanham.

Otero, G.

1999 Farewell to the Peasantry? Political Class Formation in Rural Mexico. Westview Press, Boulder.

Scrase, T.J.

2003 Precarious production, globalisation and artisan labour in the Third World. Third World Quarterly 24:449-461.

Stephen, L.

1987 Zapotec weavers of Oaxaca: Development and community control. Cultural Survival Quarterly 11:46-48.

1991 Zapotec Women. University of Texas Press, Austin. 1993 Weaving in the fast lane: Class, ethnicity, and gender in Zapotec craft commercialization. En Crafts in the World Market: The Impact of Global Exchange on Middle American Artisans, editado por J. Nash, pp. 25-57. State University of New York Press, Albany.

2005 Women's Weaving Cooperatives in Oaxaca: An indigenous response to neoliberalism. Critique of Anthropology 25:253-278.

Wodon, Q., D. Angel-Urdinola, G. Gonzalez-Konig, D. Ojeda Revah y C. Siaens

2003 Migration and poverty in Mexico's Southern States. En Mexico Southern States Development Strategy, Volumen II, Paper 16, editado por G. Hall, World Bank, Washington, DC.

Wood, W.W.

1996 Teotitlán del Valle: A maquiladora in Oaxaca, Mexico. American Anthropological Society Annual Meeting. San Francisco, CA.

2000 Flexible production, households, and fieldwork: Multisited Zapotec weavers in the Era of Late Capitalism. Ethnology 39:133-148. 


\section{Notas}

1 Los datos para este documento fueron recolectados en 2000-2004 y en 2006. Los fabricantes de canastas fueron identificados de entre 87 hogares seleccionados al azar (representando un 15\% aproximadamente de los hogares de la comunidad) que fueron encuestados como parte de un proyecto que investiga emigración y prácticas de remisión (ver Cohen 2004). Preguntando acerca de empleo y trabajo dentro de los hogares, encontramos que un $23 \%$ de los hogares encuestados incluyeron fabricantes de canastas. Para nuestro entender posterior, el trabajo y producción de oficios, campo de trabajo etnográfico adicional, incluyendo la recolección de historias orales y la observación del participante fue conducida con fabricantes de canastas en 2006.

2 Mendieta y Núñez (1960:216) cita al historiador oaxaqueño Manuel Martínez García y describe el nombre del poblado como que viene de una combinación de dos términos zapotecas, Guelaa o "medianoche," y viaá, el cual se traduce como "se ha alejado" o, de manera más concisa, el nombre del poblado se traduce como el lugar donde o que la "medianoche se ha ido".

3 Esta figura puede confundir como muchas de las familias que fabrican canastas lo hacen de manera frecuente. La mayoría de los pobladores de Guelavia calcularon que no más de 10 familias dependían en la fabricación de canastas como una parte sustancial de su ingreso.

4 Otero (1999) y Stephen (2005:263) señalan que la llegada de reformas neoliberales, particularmente aquellas reformas que siguieron a las elecciones de 1994, forzaron a muchos mexicanos rurales a una pobreza profunda. En Oaxaca, Stephen señala que los ingresos se estancaron aún cuando los costos de vivir se incrementaron. En Teotitlán del Valle, la comunidad de tejedores donde trabaja Stephen, la situación condujo a la caída en la producción de oficios y un alza en las tasas de emigración (Stephen 2005).

5 Por ejemplo, lo siguiente está publicado en la red: "El oficio de hacer jaulas para pájaros de carrizo (el bambú local) en San Juan Guelavia es transmitido de padre a hijo" (http://catterall.net/oaxaca.html, julio de 2006).

6 Encuestamos a seis familias de diferentes estratos económicos (incluyendo jornaleros con poco ingreso, un mecánico de bicicletas con poco ingreso y dueños de una tienda) por una semana con los costos asociados con la vida diaria. También recolectamos diarios de comida con cada familia. Lo que nos sorprendió fue lo similares que eran los gastos de cada hogar. 